\title{
Effect of Moderate Altitude Exposure on Human Thermal Physiological Parameters and Heat Losses in different activities
}

\author{
Haiying Wang ${ }^{1,}$, , Songtao $\mathrm{Hu}^{1, b}$ \\ ${ }^{1}$ Department of Environment and Municipal Engineering, Qingdao University of Technology, No.11 \\ Fushun Road, Qingdao, Shandong Province, China \\ awhy3305@126.com, ${ }^{\mathrm{b}} \mathrm{h}-\mathrm{lab} @ 163 . c o m$
}

\begin{abstract}
Keywords: Altitude exposure, Metabolic rate, Local skin temperature, Thermal sensation, Heat transfer.
\end{abstract}

Abstract. The effect of moderate altitude on human thermal regulation and heat loss may influence human thermal sensation and comfort. This paper aims to clarify this effect and its impact on thermal sensation. Experiments were conducted in a decompression chamber where the air parameters were controllable. Barometric conditions of $1 \mathrm{~atm}$ and $0.75 \mathrm{~atm}$ were compared. Sixteen subjects participated in two kinds of activities: sitting and treading in situ. Their metabolic rate, skin temperature and clothing surface temperature were tested. The subjects' thermal sensation votes were collected at each condition. The results showed that physiological parameters of metabolic rate, respiratory quotient and local skin temperatures in both activities were affected by moderate altitude exposure. The total heat loss of human body was calculated and it increased in hypobaric hypoxia environment. The combined effect of enhanced heat loss and decreased local skin temperature caused the change of thermal sensation.

\section{Introduction}

When people stay at mountain resorts or plateau areas, where the atmospheric pressure (AP) is lower than that at sea level, they will experience hypobaric hypoxia environment. Although most people won't get altitude sickness when the altitude is less than $3000 \mathrm{~m}$, the decreased air density and hypoxia will have some effects on physiological regulation and thermal sensation.

Hypoxia will change the oxygen saturation of blood, which will lead to thermoregulatory responses of humans. According to aviation physiology, if people were taking moderate activities their oxygen consumption would increase $10 \sim 40 \%$ in moderate hypoxia environment. The changes of oxygen consumption might cause changes of metabolic rate and related parameters. Eri Fukuda-Matsuda et al. checked physiological changes of people in hypobaric hypoxia environment from $2400 \mathrm{~m}$ to $3400 \mathrm{~m}$. Their study found that autonomic nervous activity parameters $\left(\mathrm{SpO}_{2}\right.$, mean blood pressure and heart rate) and tympanic and skin temperatures were different from the corresponding value at lower altitude [1]. Kolka et al., studied the effect of acute hypobaric hypoxia on local sweating and cutaneous blood flow, and suggested that enhanced body cooling caused some peripheral changes in hypobaric hypoxia [2]. In hypobaric environment, evaporative heat transfer was enhanced while convective heat transfer was depressed [3]. The changes in heat transfer affected people's thermal balance and thermal comfort. Studies by Chang and Santee suggested that these changes would result in a lower skin temperature and higher clothing temperature [4]. In previous study, we found that people felt cooler and became more sensitive to draught as altitude increased, and the total heat loss was increased [5]. However, the analysis about heat losses was not in detail. Further studies are necessary to explain questions like how much the total heat loss will increase and which kind of heat transfer will be increased or decreased.

As metabolic rate and heat losses are very important factors affecting body's thermal balance, the purpose of this study was to investigate their changes in hypobaric environment. In this study, physiological parameters (metabolic rate and skin temperature) along with thermal feelings in both normal AP and lower AP conditions were tested. Clothes surface temperature was also tested to calculate heat losses. 


\section{Methodologies}

The experiments were conducted in a decompression chamber, which has been introduced in reference [5]. The chamber was rearranged according to the experiment requirement, as shown in Fig. 1. The altitude simulated in the experiments was $2300 \mathrm{~m}$ (equivalent to $0.75 \mathrm{~atm}$ ).

Sixteen college students (half male and half female) participated in the experiments. They gave their informed consent prior to the study. The subjects, on average, were 22.9 (SD 3.51) years of age, weighed 57.7 (SD 9.47) kg, and were 167.9 (SD 7.37) $\mathrm{cm}$ high. Subjects were asked to avoid caffeine, alcohol, smoking, and intense physical activity at least $12 \mathrm{~h}$ prior to each experimental session.

All subjects were required to wear uniform clothes, including underwear, long-sleeved thermal underwear, sweater, trousers, socks and shoes (the estimated clothing insulation value was $1.3 \mathrm{clo}$ ). The sixteen subjects were assigned into eight groups, each group comprised of two males or two females. One group was tested each time. During all the experiments, the air temperature inside the chamber was kept at $20 \pm 1^{\circ} \mathrm{C}$, air velocity was kept below $0.1 \mathrm{~m} / \mathrm{s}$, the relative humidity was kept at $50 \pm 10 \%$. The time schedule of experiment was shown in Fig. 2 .
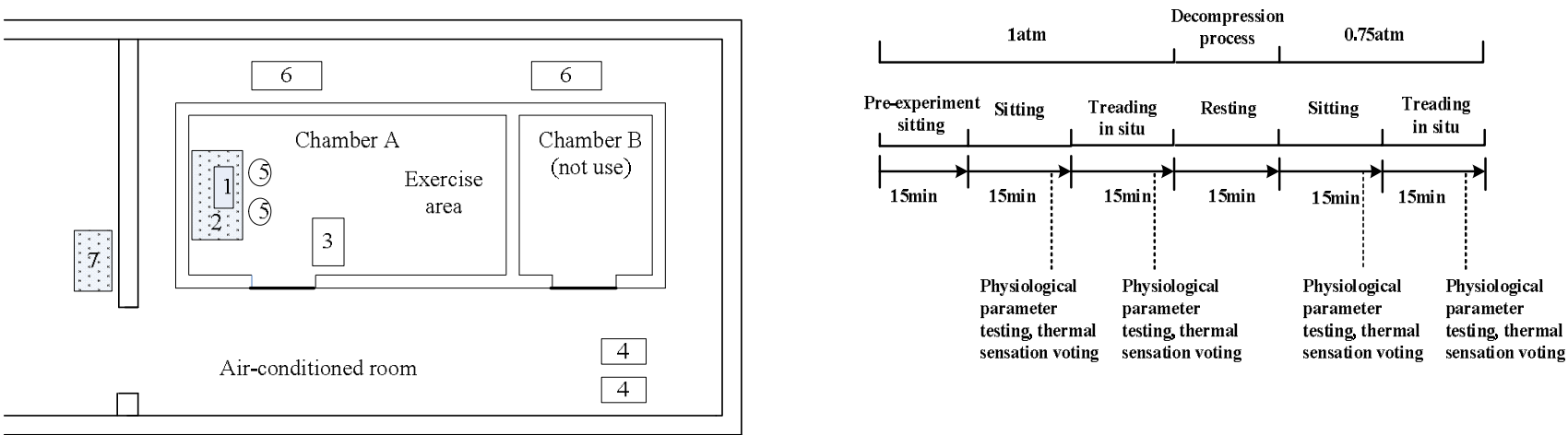

(1-air-conditioner inside the chamber, 2- table, 3-metabolic cart, 4-vacuum pump, 5-chair, 6-air conditioner in the room, 7decompression controller)

Figure1 Layout of the experiment chamber

Figure 2 Planning of the experiment

The subjects were exposed to barometric conditions of $1 \mathrm{~atm}(0 \mathrm{~m})$ and $0.75 \mathrm{~atm}(2300 \mathrm{~m})$ sequentially. During each AP, the subjects kept sitting for $15 \mathrm{~min}$ and then kept treading in situ for $15 \mathrm{~min}$. The treading frequency was about 80 steps per minute. The estimated metabolic rates for such activities were 1.1met and 2.4met according to ISO 8996 [6]. During each activity, subjects' metabolic rate and skin temperature were tested. And the subjects were required to vote on their thermal sensation. The thermal sensation vote was based on the ASHRAE/ISO seven-point thermal sensation scale [7]. Each subject should vote four times during the experiment. Skin temperatures at five points were measured by thermocouples. The five points were forehead, chest, upper arm, lower back and upper leg. Mean skin temperature (MST) were calculated with the sum of products of local skin temperatures, with weighting factors of 0.15 for forehead, 0.19 for chest, 0.10 for $\mathrm{r}$ arm, 0.19 for back and 0.37 for leg [8].Clothing surface temperature was measured by two thermocouples pasted on the surface of pants and sweater separately. As the subjects were in winter clothes, the surface temperature of clothes was almost uniform. The mean value of the two points was taken as the surface temperature.

Air velocity and relative humidity were measured by multi-parameter ventilation meter (Model 8386, TSI Inco., Minnesota, USA). The wall temperatures of the chamber were measured by thermocouples arranged in the same way depicted in reference [5]. The air temperatures at height of $0.1 \mathrm{~m}, 1.1 \mathrm{~m}, 1.7 \mathrm{~m}$ were tested by thermocouples in the activity area. The signal of thermocouples was collected by data acquisition system (Agilent 34970A, Agilent Tech., California , USA).

Metabolic rate was tested by Vmax Encore Metabolic Cart (Sensor Medics Corp., California, USA) equipped with mass flow sensor, electro chemical cell, non-dispersive infrared thermopile. All subjects attended the experiment at least $1 \mathrm{~h}$ after meal, in order to avoid specific dynamic effect of food. 
During experiments, the subjects were allowed to talk, but their talks should not relate to thermal feelings.

\section{Results and discussion}

The environmental parameters measured in experiments were shown in Table 1. The air temperature, velocity and relative humidity were close to the intended values. The temperature tested at $1.7 \mathrm{~m}$ and $0.1 \mathrm{~m}$ was used to calculate the vertical temperature difference.

Table 1 Statistic data for experiment conditions

\begin{tabular}{|l|l|l|}
\hline & Nominal values & Measured values \\
\hline Air temnerature $\left({ }^{\circ} \mathrm{C}\right)$ & 20 & $19.8(0.30)$ \\
\hline Air velocity $(\mathrm{m} / \mathrm{s})$ & $<0.1$ & $0.07(0.03)$ \\
\hline Relative humidity $(\%)$ & 50 & $47(3.7)$ \\
\hline Mean radiant temnerature $\left({ }^{\circ} \mathrm{C}\right)$ & ------ & $15.3(0.25)$ \\
\hline Vertical temperature difference & ------ & $12(031)$ \\
\hline
\end{tabular}

Measured values were mean (SD)

\section{Metabolic rate}

The metabolic rate of the 16 subjects was shown in Fig. 3. For all the subjects, their metabolic rate depended significantly on activity and AP. The metabolic rate of male subjects was a little higher than females, but the difference was not significant. The average metabolic rates for sitting and treading were 1.09 met and 2.24 met at $1 \mathrm{~atm}$, which were close to the estimated values. The metabolic rates increased to $1.47 \mathrm{met}$ and 3.09 met at $0.75 \mathrm{~atm}$. The increment of metabolic rate was $34.9 \%$ and $39.2 \%$ for the two activities. When exposed to hypoxia environment, people's basal metabolisms usually increase. According to reference, basal metabolisms of natives living at $1800 \mathrm{~m}$ altitude were $31 \%$ higher than people living at sea levels [9]. In this study, all subjects were living in sea level areas. When exposed to hypobaric hypoxia environment of $2300 \mathrm{~m}$, their metabolic rate increased immediately. Since metabolic rate was related to oxygen consumption and respiratory quotient (RQ), the changes of oxygen consumption and RQ were further analyzed in Fig. 4 and Fig. 5.

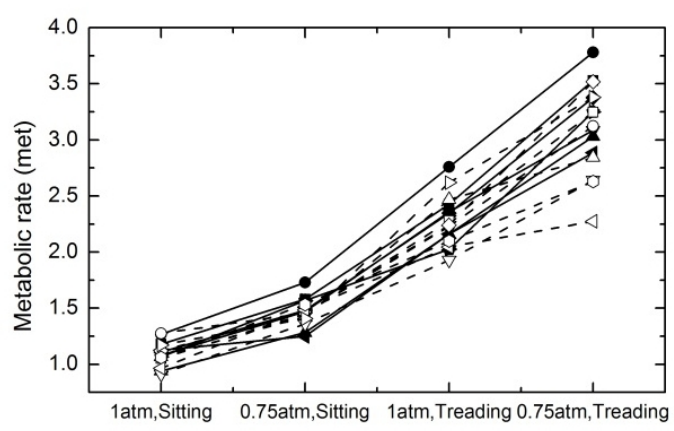

Figure 3 Metabolic rate at different conditions

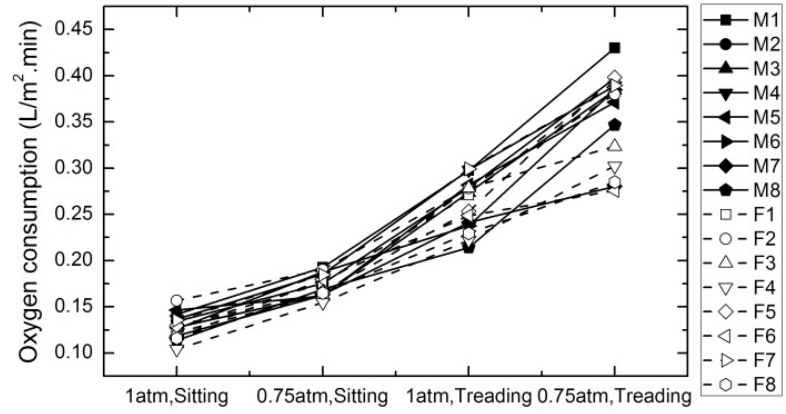

(M represents male subject, $\mathrm{F}$ represents female subject) Figure 4 Oxygen consumption at different conditions

In Fig. 4, the oxygen consumption was calculated on base of body area. The change of oxygen consumption was similar to that of metabolic rate. At $0.75 \mathrm{~atm}$, the oxygen consumption increased $33.2 \%$ for sitting and $37.8 \%$ for treading in situ compared to $1 \mathrm{~atm}$. 


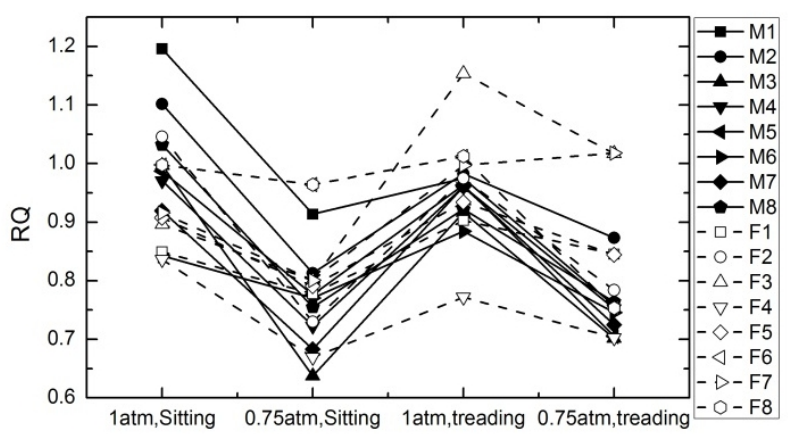

Figure 5 RQ at different conditions

RQ represented the ratio of carbon dioxide produced to the amount of oxygen consumed by the individual. RQ was useful in deciding energy equivalent of oxygen consumption. At $1 \mathrm{~atm}$, the average RQ for sitting and treading in situ was 0.965 and 0.96 , at $0.75 \mathrm{~atm}$, the average RQ was 0.785 for both activities. The results showed that RQ was not related to activities, it just decreased as AP decreased. This was similar to what had found in the experiments done by Cui [10]. Usually RQ was influenced by vigorous activities, nutrient transformation and energy source of the body. When people took vigorous activities, anaerobic metabolism would cause the increase of RQ [11]. The activities in the experiments were not vigorous enough to change RQ. So the variation of RQ should be caused by other factors. During hypoxia acclimatization process, the energy metabolism of organism adjusted to adapt to the change of oxygen. Acute hypoxia would block the aerobic metabolism of sugar and the corresponding change in selective energy substance was an important link in hypoxia acclimatization [12]. So we attributed the change of RQ to adjustment of body energy substance.

\section{Skin temperature}

The local skin temperatures tested and MST calculated were shown in Figure 6. The temperatures of chest and arm changed little in the four experimental conditions. The temperatures of forehead and back both decreased as AP decreased, temperature at leg increased as AP decreased. The influence of activity on the three local skin temperatures was less than AP.

As to MST, it increased a little as AP decreased and decreased slightly as activity increased. The temperature decrement of chest and back was compensated by temperature increment of leg, so the change of MST at different AP exposure was quite small. When treading in situ, the increased body moving velocity would enhance the body heat loss and cause the change of MST.

The MST of male and female subjects was compared in Figure 7. The MST of males was a little higher than females in all conditions. The average difference of MST between male and female in both activities at $1 \mathrm{~atm}$ was $0.21^{\circ} \mathrm{C}$, the difference increased to $0.42^{\circ} \mathrm{C}$ at $0.75 \mathrm{~atm}$. The difference was not affected by activities. It seemed that altitude exposure increased the gender difference of MST.

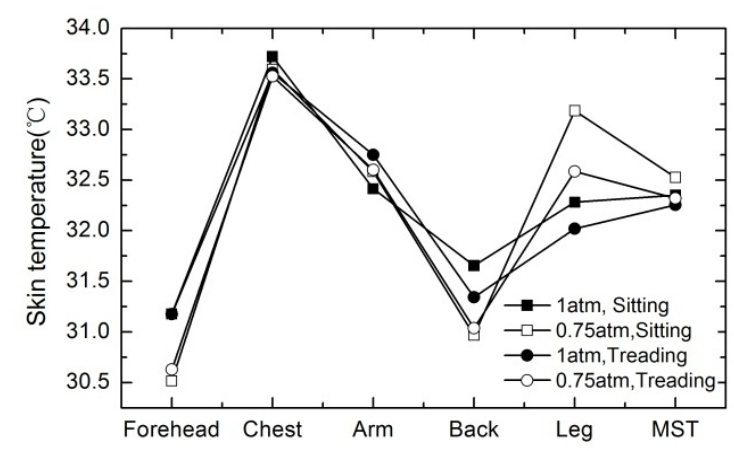

Figure 6 Skin temperatures of different parts

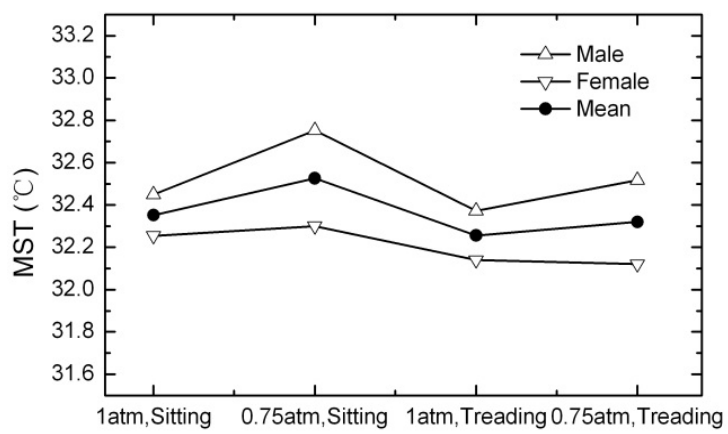

Figure 7 MST of males and females

Hedio et al. studied people's thermal comfort at 0.7atm, and found that in warm environment, subjects' local skin temperature changed, they supposed that the blood flow in the body would change to compensate for hypoxia under hypobaric conditions [13]. Studies by Kolka et al. also showed that 
altitude exposure had some effects on skin blood flow and local skin temperature [2]. Based on these references, it was inferred that moderate altitude exposure had little effect on MST, yet it would cause changes in local skin temperatures. In the experiments, only five local skin temperatures were tested. For other parts of skin, whether the skin temperature would change under lower AP and how it changes were still unclear and should be studied further.

\section{Clothing surface temperature}

The mean clothing surface temperatures were shown in Table 2. The surface temperatures were affected by activities and AP. When AP was kept constant, the surface temperature decreased as activity increased. It decreased $1.19^{\circ} \mathrm{Cat} 1 \mathrm{~atm}$ and $1.36^{\circ} \mathrm{C}$ at $0.75 \mathrm{~atm}$ for the two activities. This effect was due to the increased body movement, which enhanced the body heat transfer. The clothing surface temperature increased $0.93^{\circ} \mathrm{C}$ at sitting and $0.76^{\circ} \mathrm{C}$ at treading in situ as AP decreased. According to studies by Chang and Santee [4], the effect of AP on clothing surface temperature was due to the depressed convective heat transfer. Since radiant heat transfer was related to clothing surface temperature directly, this temperature change would cause the change of radiant heat loss.

Table 2 Tested mean clothing surface temperature

\begin{tabular}{|l|l|l|}
\hline AP & Activity & Clothino surface temnerature $\left({ }^{\circ} \mathrm{C}\right)$ \\
\hline \multirow{2}{*}{$1 \mathrm{~atm}$} & Sitting & 25.2 \\
\cline { 2 - 3 } & Treading & 24.0 \\
\hline \multirow{2}{*}{$0.75 \mathrm{~atm}$} & Sitting & 26.1 \\
\cline { 2 - 3 } & Treading & 24.8 \\
\hline
\end{tabular}

\section{Mean thermal sensation vote}

Subjects' mean thermal sensation vote (MTSV) was shown in Fig. 8. MTSV increased as activity increased, which followed the regular rules. When subjects were sitting or treading in situ, the MTSV declined as AP dropped. At 0.75atm, the MTSV decreased 0.56 at sitting and 0.41 at treading in situ compared to $1 \mathrm{~atm}$. The result was consistence with conclusions we had found before. The MTSV of female was lower than that of males at all conditions. Generally, females were more sensitive to cold and in some studies they were found feeling cooler than males [14].

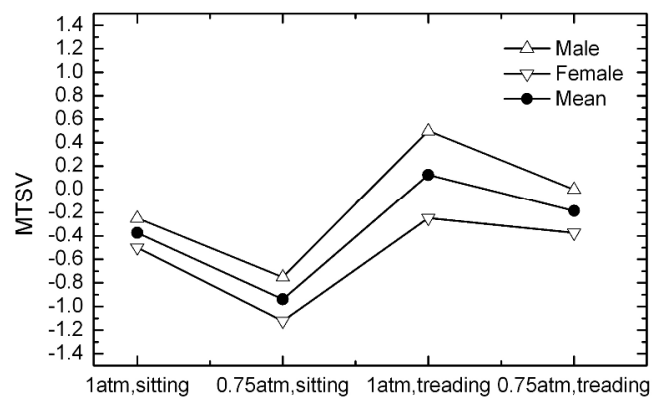

Figure 8 MTSV in experiments

Since metabolic rate increased, it seemed a little contradict that people felt cooler when AP decreased. People's thermal sensation was not only related to heat gains, but also related to heat losses. To make it more clear, the heat losses were calculated in details.

\section{Corrections on heat transfer equations and calculation}

The heat transfer equations calculating convective heat, radiant heat, evaporative heat and respiratory heat were mainly referenced from 2005 Handbook ASHRAE [7] and would not be listed out here anymore. Considering the effect of AP and body movement on heat transfer, the following corrections were made. 
For convective heat transfer coefficient: $h_{c c}=h_{c}\left(p_{t} / 101.3\right)^{0.55}$

Where $h_{c}$ was convective heat transfer coefficient, $\mathrm{W} /\left(\mathrm{m}^{2} . \mathrm{K}\right), h_{c c}$ was the corrected convective heat transfer coefficient, $\mathrm{W} /\left(\mathrm{m}^{2} . \mathrm{K}\right) ; p_{t}$ was the local atmospheric pressure, $\mathrm{kPa}$.

For Evaporative heat transfer coefficient: $\quad h_{e c}=h_{e}\left(101.3 / p_{t}\right)^{0.45}$

Where $h_{e}$ was the evaporative heat transfer coefficient, $\mathrm{W} /\left(\mathrm{m}^{2} . \mathrm{kPa}\right), h_{e c}$ was the corrected evaporative heat transfer coefficient, $\mathrm{W} /\left(\mathrm{m}^{2} . \mathrm{kPa}\right)$.

The effect of body movement on convective heat transfer was corrected by effective velocity using the following equation [15]: $\quad v_{\text {eff }}=v_{a}+w \quad \mathrm{~m} / \mathrm{s}$

Where $v_{\text {eff }}$ was the effective velocity, $\mathrm{m} / \mathrm{s} ; v_{a}$ was the air velocity, $\mathrm{m} / \mathrm{s}$; and $w$ was the walking speed, $\mathrm{m} / \mathrm{s}$. And $w$ was calculated by: $w=0.0052 \times(M-58) \quad \mathrm{m} / \mathrm{s}$

Where $M$ was rate of metabolic heat production, $\mathrm{W} / \mathrm{m}^{2}$. According to the measured metabolic rate, $w$ was $0.37 \mathrm{~m} / \mathrm{s}$ at treading in situ.

As walking decreases clothing insulation, the change in clothing insulation $\Delta I c l$ at treading in situ was estimated from the standing intrinsic insulation $\mathrm{Icl}$ of the ensemble and the walking speed $(w)$ in steps per minute [16-18]: $\Delta I_{c l}=-0.504 I_{c l}-0.00281 w+0.24$

According to equation (5), the corrected clothing insulation at treading in situ was 0.81 clo.

Heat losses were calculated and compared in Table 3.

Table 3 Heat loss in experiment conditions

\begin{tabular}{|c|c|c|c|c|c|c|c|}
\hline \multicolumn{2}{|c|}{ Experiment conditions } & $\begin{array}{l}\text { Metabolic } \\
\text { rate } \\
\left(\mathrm{W} / \mathrm{m}^{2}\right)\end{array}$ & $\begin{array}{l}\text { Convective } \\
\text { heat } \\
\text { transfer } \\
\left(\mathrm{W} / \mathrm{m}^{2}\right)\end{array}$ & \begin{tabular}{|l} 
Radiant \\
heat \\
transfer \\
$\left(\mathrm{W} / \mathrm{m}^{2}\right)$
\end{tabular} & $\begin{array}{l}\text { Evaporative } \\
\text { heat transfer } \\
\left(\mathrm{W} / \mathrm{m}^{2}\right)\end{array}$ & $\begin{array}{l}\text { Reparatory } \\
\text { heat } \\
\text { transfer } \\
\left(\mathrm{W} / \mathrm{m}^{2}\right)\end{array}$ & $\begin{array}{l}\text { Total heat } \\
\text { loss } \\
\left(\mathrm{W} / \mathrm{m}^{2}\right)\end{array}$ \\
\hline \multirow{3}{*}{ Sitting } & 1atm & 63.2 & 17.3 & 32.5 & 14.1 & 6.5 & 70.4 \\
\hline & $0.75 \mathrm{~atm}$ & 85.3 & 17.3 & 35.7 & 25.2 & 8.8 & 87 \\
\hline & $\begin{array}{l}\text { Relative } \\
\text { change (\%) }\end{array}$ & 34.9 & 0 & 9.9 & 78.7 & 34.9 & 23.6 \\
\hline \multirow{3}{*}{ Treading } & $1 \mathrm{~atm}$ & 131.7 & 31.7 & 29.8 & 55.5 & 13.5 & 130.5 \\
\hline & $0.75 \mathrm{~atm}$ & 183.3 & 32.0 & 32.48 & 84.5 & 18.8 & 167.8 \\
\hline & $\begin{array}{l}\text { Relative } \\
\text { change (\%) }\end{array}$ & 39.2 & 0.95 & 9.0 & 52.2 & 39.2 & 28.6 \\
\hline
\end{tabular}

Convective heat transfer didn't change as AP decreased in both activities. Although the convective heat transfer coefficient was decreased at $0.75 \mathrm{~atm}$, the clothing surface temperature was increased, and the temperature difference in convective heat transfer was enlarged a little, which compensated the decrease of convective heat transfer coefficient. Since convective heat transfer was believed to be decreased when AP dropped, this result was a little different from what we had expected.

The increase of clothing surface temperature at 0.75 atm enhanced the Radiant heat transfer $9.9 \%$ at sitting and $9 \%$ at treading in situ compared to $1 \mathrm{~atm}$.

Respiratory heat transfer was proportional to metabolic rate. As metabolic rate was increased at $0.75 \mathrm{~atm}$ the respiratory heat transfer was also increased.

The evaporative heat transfer included natural diffusion of water through the skin and evaporative heat loss by regulatory sweating. Under $0.75 \mathrm{~atm}$, it increased $78.7 \%$ and $52.2 \%$ at sitting and treading in situ respectively.

Fig. 9 compared the proportion of all the heat losses. The proportion of respiratory heat $\left(Q_{\text {res }}\right)$ changed little and was about $10 \%$ in all conditions. When AP decreased, the proportion of convective heat $(C)$ and radiant heat $(R)$ were both reduced in the two activities, while the proportion of evaporative heat $\left(E_{s k}\right)$ was increased. As proportion of heat losses also affected thermal sensation, this might cause the change of MTSV at lower AP.

The total heat loss was elevated $23.6 \%$ at sitting and $28.6 \%$ at treading in situ under $0.75 \mathrm{~atm}$. Although the growing rate of heat loss was less than the increment of metabolic rate, the enhanced heat 
transfer and changes of heat loss proportion at lower AP could explain partly why people felt cooler under altitude exposure. Another reason was related to the changes of local skin temperature.

Although, the MST didn't change obviously at $0.75 \mathrm{~atm}$, the local skin temperature at forehead, back and leg changed. There were cold receptors and warm receptors distributed in the skin. The cold receptor was sensitive to cold and the warm receptor was sensitive to warm. The cold and warm receptors were cutaneous thermo-receptors that provided the first thermal feedback signals, giving rise or down to thermal sensations, physiological adjustments and eventually to decisions relating to the pleasantness or comfort that the environment and associated responses evoke [19]. The distribution of thermo-receptors was quite different and there were more cold receptors on the skin than warm receptors. At forehead and back, there were only cold receptors. As skin temperature of these areas declined, cold feeling signals were sent to the thermoregulation center. Although temperature at leg increased and there were warm receptors on leg, the number of warm receptors was very limited compared to cold receptors on that area. Study by Cotter and Taylor showed that the thermal condition of head dominated whole-body thermal sensation and discomfort [20]. So the thermal status of forehead, an important part of head, might have more powerful influence on thermal sensation. We compared the local skin temperature at forehead and back with MTSV, see Fig. 10. The MTSV showed a positive linear correlation $(\mathrm{P}<0.05)$ with skin temperature of forehead and a positive tendency with skin temperature of back. The decreased skin temperature at chest and forehead gave cold signals and could make people feel cooler at $0.75 \mathrm{~atm}$.

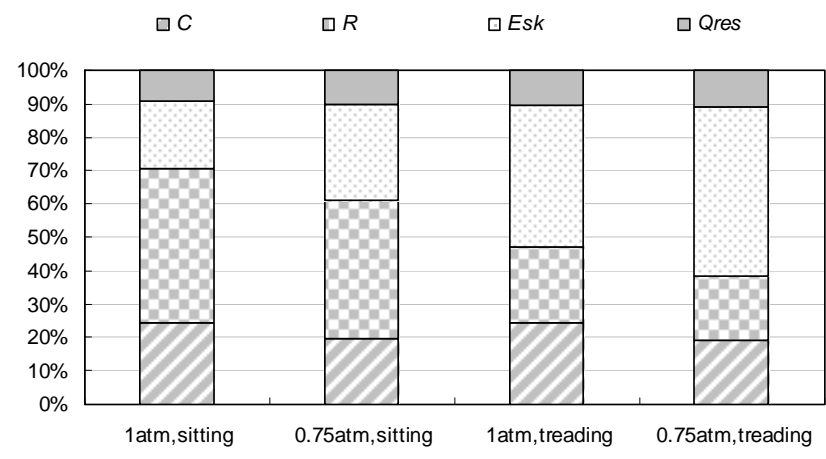

Figure 9 Proportions of heat loss

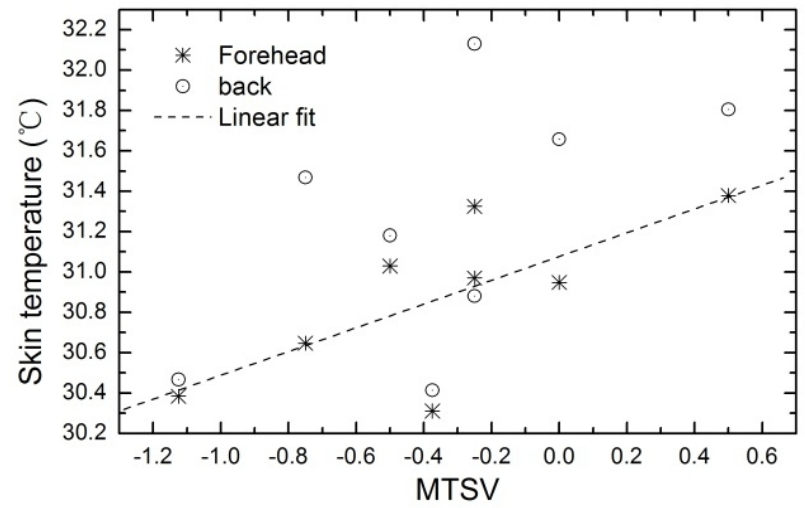

Figure10 MTSV and local skin temperature

The above analysis showed that under hypobaric hypoxia environment, the combining effect of increased heat losses and decreased local skin temperature caused the decline of thermal sensation.

\section{Conclusions}

In the present work, physiological parameters of metabolic rate, RQ and local skin temperatures in two activities had been found to be affected by moderate altitude exposure. Metabolic rate at $0.75 \mathrm{~atm}$ increased $37.0 \%$ averagely in the two activities. RQ decreased from 0.96 at 1 atm to 0.785 at $0.75 \mathrm{~atm}$. The change of MST was not significant, but local skin temperatures at forehead, chest and leg changed. Heat transfer calculated showed that under lower AP people's total heat loss was enhanced. The combining effect of increased heat loss, changes of heat loss proportion and local skin temperature change was summarized as the cause of declined thermal sensation under moderate altitude exposure. As skin blood flow was not tested, the deeper physiological reason that caused the changes of local skin temperature was not quite clear and should be studied further.

\section{Acknowledgments}

This work is financially supported by Natural Science Foundation of Shandong Province (China) through grant No. R2014JL041, and by the National Key Basic Research and Development Program of China (the 973 Program) through grant No. 2012CB720100. 


\section{References}

[1] Eri Fukuda-Matsuda, Makiko Yamada, Kyoko Tanobe et al.. Peripheral circulation monitored by surface temperature and autonomic nervous function in hypobaric hypoxic environment: effect of sub-maximal exercise, International Journal of Environmental Health Research27: (2007)53-60.

[2] M.A. Kolka, L.A. Stephenson, P.B. Rock and R.R. Gonzalez, Local sweating and cutaneous blood flow during exercise in hypobaric environments, Journal of Applied Physiology62: (1987) 2224-2229.

[3] MK. Iwajlo, Heat and mass exchange processes between the surface of the human body and ambient air at various altitudes, International Journal of Biometeorology43: (1999) 38-44.

[4] SK Chang, WR. Santee, Clothing insulation in a hypobaric environment, Aviation, Space, and Environmental Medicine67: (1996) 827-834.

[5] Haiying Wang, Songtao Hu, Guodan Liu, etc. Experimental study of human thermal sensation under hypobaric conditions in winter clothes, Energy and Buildings42: (2010) 2044-2048.

[6] ISO/TC 159. ISO 8996. Ergonomics of the thermal environment-Determination of metabolic heat production, International organization for standard, 2004.

[7] 2005 ASHRAE handbook fundamentals. Inch-pound ed. Published 2005 by ASHRAE in Atlanta, GARuth Nilsen and Bodil Nielsen. Measurement of mean skin temperature of clothed persons in cool environments, Eur J. of Appl. Physiol.53: (1984) 231-236.

[8] Ruth Nilsen and Bodil Nielsen. Measurement of mean skin temperature of clothed persons in cool environments, Eur J. of Appl. Physiol.53: (1984) 231-236.

[9] Yanbo Gao. Altitude sickness, Tsinghai people's publishing house, China, 1982.

[10] Weilin Cui, Qin Ouyang, Yingxin Zhu. Effect of air pressure on human thermal sensation and physiological parameters. Proceedings of Indoor Air: (2014), Hong Kong.

[11] Bubiao Wang and Ming Hua. Exercise physiology, Higher education publishing house, Beijing, China, 2006.

[12] YuqiGao, Jian Chen, Wenxiang Gao, etc. Adjustment of energy metabolism and its mechanism in high altitude hypoxia environment, Journal of High Altitude Medicine. 19: (2009) 3-4.

[13] O. Hideo, K. Satoru, S. Teruyuki, et al, The effects of hypobaric conditions on man's thermal responses, Energy and Buildings16: (1991) 755-763.

[14] KC. Parsons, The effects of gender, acclimation state, the opportunity to adjust clothing and physical disability on requirements for thermal comfort, Energy and Buildings 34: (2002) 593-599.

[15] International Organization for Standardization. Hot environments analytical determination and interpretation of thermal stress using calculation of required sweat rate, ISO 7933. International Organization for Standardization, Geneva, 2004

[16] McCullough, E.A. and S. Hong. A data base for determining the decrease in clothing insulation due to body motion, ASHRAE Transactions100: (1994) 765-773.

[17] G. Havenith, H. O. Nilsson. Correction of clothing insulation for movement and wind effects, a meta-analysis, Eur J. of Appl. Physiol. 92: (2004) 636-640.

[18] Havenith, G., Heus, R. and Lotens, V. Resultant clothing insulation: a function of body movement, posture, wind, clothing and ensemble thickness. Ergonomics33: (1990) 67-84.

[19] H. Hensel. Thermo-reception and Temperature Regulation, London: Academic Press, 1981.

[20] Cotter, J.D., and Taylor, N.A.S.. Distribution of cutaneous sudomotor and alliesthesial thermosensitivity in mildly heat-stressed humans: an open-loop approach, J. Physiol. 565: (2005) 335-345. 